\title{
ON A SPONTANEOUS DECENTRALIZED MARKET PROCESS
}

\author{
$\underline{\text { Satoru Fujishige }}$ \\ Kyoto University, Japan \\ fujishig@kurims.kyoto-u.ac.jp \\ Zaifu Yang \\ University of York, United Kingdom \\ zaifu.yang@york.ac.uk
}

\begin{abstract}
We examine a spontaneous decentralized market process widely observed in real life labor markets. This is a natural random decentralized dynamic competitive process. We show that this process converges globally and almost surely to a competitive equilibrium. This result is surprisingly general by assuming only the existence of an equilibrium. Our findings have also meaningful policy implications.
\end{abstract}

Keywords: Spontaneous market process, decentralized market, competitive equilibrium.

JEL classification: C71, C78, D02, D44, D58.

This research is supported by JSPS KAKENHI Number (B)25280004 and DERS RIS grant of York. We thank Tommy Andersson, Bo Chen, Yan Chen, Miguel Costa-Gomes, Vincent Crawford, Peter Eso, Sanjeev Goyal, Yorgos Gerasimou, Kazuya Kamiya, Michihiro Kandori, Fuhito Kojima, Alan Krause, Jingfeng Lu, Eric Mohlin, Alex Nichifor, In-Uck Park, Herakles Polemarchakis, Alvin Roth, Hamid Sabourian, Yaneng Sun, Satoru Takahashi, Dolf Talman, Mich Tvede, Hao Wang, Siyang Xiong, William Zame, Jie Zheng, and many participants at Bristol, Cambridge, Chinese Academy of Sciences, Kobe, Lund, NUS (Singapore), Oxford, Peking, St Andrews, SWUFE, Tilburg, Tokyo, Tsinghua, 2016 China Meeting of Econometric Society (Chengdu), 2016 Workshop of Midlands Economics Theory and Applications (York), and General Equilibrium Workshop (York) for their valuable comments which helped us improve the paper. Any errors are, of course, our own responsibility. The current paper is a revised version of Fujishige \& Yang (2015). 


\begin{abstract}
"Every individual endeavors to employ his capital so that its produce may be of greatest value. He generally neither intends to promote the public interest, nor knows how much he is promoting it. He intends only his own security, only his own gain. And he is in this led by an invisible hand to promote an end which was no part of his intention. By pursuing his own interest he frequently promotes that of society more effectually than when he really intends to promote it." Adam Smith, The Wealth of Nations (1776).
\end{abstract}

\title{
1. INTRODUCTION
}

$\mathbf{O}$ ne of the central issues of economic research is to study market processes by which equilibrium prices or wages can be formed. The basic idea of market processes can be traced back at least to Smith (1776), who used his famous metaphor 'the Invisible Hand' to describe the self-regulating nature of a decentralized free market where the spontaneous action of rational economic agents driven by self-interest will produce a socially desirable outcome.

Walras (1874) suggested a price adjustment process known as the tâtonnement process. In it, a fictitious auctioneer announces a price for one good, collecting all the demands for the good, adjusting the price by the law of demand and supply until an equilibrium in this single good market is reached. The same procedure applies to the remaining goods successively one by one. This sequential procedure is, however, very restrictive. A major improvement was made by Samuelson $(1941,1948)$ who proposed a simultaneous tâtonnement process. Arrow \& Hurwicz (1958), Hahn (1958), and Arrow et al. (1959) proved that Samuelson's process converges globally to an equilibrium provided that all goods are perfectly divisible and substitutable. Scarf (1960) showed by examples that this process, however, does not work if the goods are complementary. ${ }^{1}$ More recently, efficient market processes such as auctions and job matching have been developed to deal with more realistic markets that permit indivisibilities; see Crawford \& Knoer (1981), Kelso \& Crawford (1982), Gul \& Stacchetti (2000), Milgrom (2000, 2004), Ausubel \& Milgrom (2002), Perry \& Reny (2005), Ausubel (2004, 2006), and Sun \& Yang (2009,

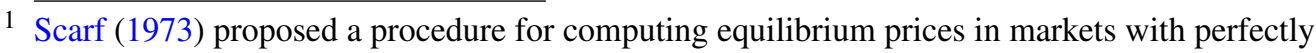
divisible goods. 
2014) among others. ${ }^{2}$ All these processes are deterministic and tâtonnement, and are adjusted by an auctioneer in an orderly manner.

Departing from the deterministic market processes, we will examine a random decentralized dynamic competitive market process widely observed in real life labor markets. Although this is a natural spontaneous market process, there has been no formal analysis on it in the literature. The first and foremost important question arises here: will this process generate a desirable economic outcome? This is a significant question as it concerns whether decentralized and uncoordinated markets, notably labor markets, can be operated efficiently or not. Our major finding is that starting from an arbitrary market state this process converges with probability one to a competitive equilibrium in finite time, yielding a Pareto optimal outcome. To our surprise, this result holds true by requiring only a minimal assumption that the market has an equilibrium. It does not rely on any particular condition on the underlying market structure and can therefore admit every possible existence condition. It can accommodate indivisibility, complementarity, and uncertainty or randomness, which are prominent features of the market.

The spontaneous decentralized market process under consideration has the following basic features. Firstly, in the market firms and workers are heterogeneous and inherently indivisible, and workers meet directly and randomly in pursuit of higher payoffs over time. Each firm hires as many workers as it wishes, having a revenue value for each group of workers. Each worker has preferences over firms and salaries but works for at most one firm. When employees work for a firm, they generate a joint revenue which is then split among the firm and its employees.

Secondly, all agents (firms or workers) are driven by self-interest and make their own decisions independently and freely and their activities are neither coordinated nor organized. A firm and a group of workers may form a new coalition if they can divide their joint payoff among themselves to make no member of the coalition worse off and at least one member strictly better off. In this process, the firm will probably dismiss some of its own workers and recruit workers from other firms to be called deserted firms, and every deserted firm will at least temporally not change its contracts for its remaining workers. This process is called a coalition improvement with the status quo maintaining rule.

This status quo maintaining rule reflects a common practice in real life

2 See Bajari and Hortaçsu (2004) for a survey on internet auctions. 
business. For instance, if a star professor moves from university A to university $\mathrm{B}$, the former will not alter its contracts with the remaining faculty members at least for a short period of time. This process is only assumed to occur with a positive probability conditional on the current state and time. The assumption on such a probability is intended to capture significant uncertainty about market opportunities due to the nature of decentralized decision-making; see e.g., Kelso \& Crawford (1982) and Roth \& Vande Vate (1990). For example, even a most confident employer, say, a top academic department, cannot be $100 \%$ certain that its vacancies would be fully filled. Furthermore, the assumption is a natural requirement that although information about the market is dispersed and incomplete, it should flow freely enough so that all market participants are sufficiently well informed and can therefore have a chance to respond to newly arrived opportunities. The assumption of a positive probability could be viewed as a degree of market transparency.

Thirdly, this process is spontaneous in the sense that it is the result of human self-interested action but not of conscious human design such as auction or matching design. ${ }^{3}$ In Hayek (1988), this kind of market process is called a spontaneous order and is a natural free market process. This process is not, however, a tâtonnement ${ }^{4}$ because trading is permitted even if the market is not in equilibrium. In other words, at each time, if a worker is matched with a firm, this worker will provide service for the firm in exchange for a wage from the firm whether it is an equilibrium wage or not. As long as the market has not reached an equilibrium, it will create incentives for some agents to deviate from the current state. This type of deterministic non-tâtonnement process has been studied by Hahn (1962), Hahn \& Negishi (1962), Negishi (1961, 1962), Uzawa (1962), Arrow \& Hahn (1971, Chapter XIII), and Fisher (1972, 1974, 1989).

Fourthly, this process is not monotonic and permits chaotic, cyclic and myopic behaviors. In the process deserted firms and dismissed workers generally become worse off and thus the total welfare need not be monotonic. A worker may sequentially work for several firms because a latter firm offers a better salary or the worker may have been fired previously; conversely, the same firm hires different workers over time for the same positions as workers who

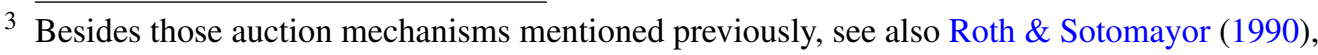
Hatfield \& Milgrom (2005), Ostrovsky (2008), and Kojima \& Pathak (2009) for a variety of matching models.

${ }^{4}$ Recall that a tâtonnement process permits trade to take place only at equilibrium prices. 
come later may either work more efficiently or demand lower salaries. It is not uncommon to see that a worker eventually returns to her previous employer but with a different contract. It is also possible that in the process a worker may get a remarkably attractive position at one time but get fired at another time. The process can be chaotic and occasionally cyclical as firms and workers meet directly and randomly, haggling for better deals, and coalitions can be formed hastily and can also dissolve instantly whenever better opportunities arise. Yet, the rules of this spontaneous process are simple, transparent, and detail-free according to the doctrine of Wilson (1987).

Our main result demonstrates that, starting from an arbitrary market state of a matching between firms and workers with a system of salaries, the above random decentralized dynamic process, where every possible coalition improvement with the status quo maintaining rule conditional on the current state and time occurs with a positive probability, almost surely converges in finite time to a competitive equilibrium of the market consisting of an efficient matching between firms and workers and a scheme of supporting salaries (Theorem 1 and Corollary 1), resulting in a Pareto optimal outcome. This result holds true for any market environment as long as there exists a competitive equilibrium with an integral vector of equilibrium salaries or prices. ${ }^{5}$ The consideration of such equilibrium prices is very natural and practical, because any transaction in real life business can only happen in integer number of monetary units. A number of sufficient conditions are known to ensure the existence of such an equilibrium. ${ }^{6}$ Among them, the Gross Substitutes condition given by Kelso \& Crawford (1982) has been widely used and requires every firm to view all workers as substitutes, subsuming the assignment model by Koopmans \& Beckmann (1957), Shapley \& Shubik (1971), Crawford \& Knoer (1981), and Demange et al. (1986) as a special case. ${ }^{7}$ A crucial step toward establishing the major result of the paper is to prove that the spontaneous decentralized random process does not get stuck in cycles endlessly. To this end, we develop a novel

${ }^{5}$ In contrast, to our best knowledge, in the deterministic settings there is no general existing process that guarantees to find a competitive equilibrium in an economy with indivisibilities if one assumes only the existence of an equilibrium; see those references mentioned in the second paragraph.

${ }^{6}$ See Kelso \& Crawford (1982), Ma (1998), Sun \& Yang (2006), Milgrom \& Strulovici (2009), Baldwin \& Klemperer (2013), Fujishige \& Yang (2015), and Murota (2016).

${ }^{7}$ Such models are also called unit-demand models where every consumer demands at most one item (see also Shapley \& Scarf (1974)) or every person needs only one opposite sex partner (see Gale \& Shapley (1962)). 
technique to show the existence of a finite sequence of successive coalition improvements with the status quo maintaining rule from any initial market state to a competitive equilibrium in the market (Theorem 2).

The current study on the spontaneous decentralized market process may help deepen our understanding of Adam Smith's Invisible Hand in complex economic environments and offer a theoretic explanation as to why the spontaneous decentralized market process widely observed in labor markets can perform well and thus justify its very existence. Our findings might also have some interesting policy implications: in general, free markets can work well as Hayek (1944) had passionately advocated, almost surely resulting in socially efficient outcomes in a self-interested and law-abiding but seemingly chaotic and random economic environment, and in particular the price system can marvellously aggregate and communicate information "in a system in which the knowledge of the relevant facts is dispersed among many people" as Hayek (1945) had believed. ${ }^{8}$ A caveat is that free markets cannot unconditionally function properly, and in order for them to work well, the government should promote and improve market transparency so as to facilitate the convergence of such market processes. ${ }^{9}$ We also discuss (in Section 5) under what circumstance firms can avoid (sometimes controversial) massive dismissals.

We conclude this introductory section by reviewing several related studies. In a pioneering study Kelso \& Crawford (1982) introduced a general job matching market where each firm can hire several workers and each worker is employed by at most one firm. They developed a salary adjustment process that converges to an equilibrium provided that every firm treats all workers as substitutes. Although they stress that pervasive uncertainty is an essential feature of the labor market, they do not deal with uncertainty and their process is a deterministic market process. In a seminal article Roth \& Vande Vate (1990) reexamined the marriage matching model of Gale \& Shapley (1962) in which each man tries to marry his favorite woman and vice versa, and established a decentralized random process for the model; see Ma (1996) for a further study on this process. Kojima \& Ünver (2008) generalized the marriage model in a substantial way to allow for instance each college to

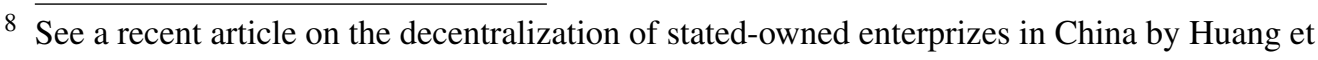
al. (2017).

9 Since 1980s, indeed many governments around the world require every employer to publicly announce its job openings at least several weeks or months in advance before the closing date. 
admit many students and each student to attend several colleges. ${ }^{10}$ They investigated a decentralized random process for a pairwise stable matching outcome and established a probabilistic convergence. Chen et al. (2016) examined a random decentralized process for the assignment market, as a counterpart of the deterministic processes proposed by Crawford \& Knoer (1981) and Demange et al. (1986). Nax \& Pradelski (2015) discussed a similar issue from the viewpoint of evolutionary dynamics. Ma \& Li (2016) studied a decentralized probabilistic double auction process for a financial market.

A crucial and well-recognized difference between the matching models ${ }^{11}$ and the competitive market models ${ }^{12}$ is that the matching models do not involve (or have flexible) prices nor have a system of competitive prices to support a stable matching outcome, which is the often-used notion of solution to matching models and generally weaker than the concept of competitive equilibrium (see Quinzii (1984)). Feldman (1974) and Green (1974) studied deterministic decentralized processes for certain subclasses of non-transferable utility games. Their approaches do not apply to the labour market or matching models where indivisibility is involved. Chung (2000), Diamantoudi et al. (2004), Klaus \& Klijn (2007), and Biró et al. (2014) investigated random processes for roommate and marriage matching models.

The rest of the paper is organized as follows. Section 2 presents the model and basic concepts. Section 3 contains the main results. Section 4 introduces the thought experimental procedure for proving the key result (Theorem 2). Section 5 examines the case of Gross Substitutes which can help firms avoid massive dismissals. Section 6 concludes.

\section{THE MODEL}

Consider a general labor market with a finite number of heterogeneous firms and workers. Formally, let $F$ be the set of $m$ firms and $W$ the set of $n$ workers, respectively. We assume that each firm can hire as many workers as it wishes

${ }^{10}$ They assume that agents on one side of the market have substitutable preferences and those on the other side have responsive preferences.

${ }^{11}$ Studied by Gale \& Shapley (1962), Roth \& Sotomayor (1990), Roth \& Vande Vate (1990), and Kojima \& Ünver (2008) among others.

${ }^{12}$ Studied by Koopmans \& Beckmann (1957), Arrow \& Hurwicz (1958), Shapley \& Shubik (1971), Shapley \& Scarf (1974), Kelso \& Crawford (1982), Gul \& Stacchetti (1999), Ausubel (2006), and Sun \& Yang $(2006,2009)$. 
but each worker can work for at most one firm. Each firm $j \in F$ has an integervalued and weakly increasing revenue function $R^{j}: 2^{W} \rightarrow \mathrm{Z}$ with $R^{j}(\emptyset)=0$. Namely, when firm $j$ hires a group $B \subseteq W$ of workers, it has a revenue of $R^{i}(B)$ in units of money thus being an integer value. Given a scheme of salaries $s^{j}=\left(s_{i}^{j} \mid i \in W\right) \in \mathbf{R}_{+}^{W}$ for firm $j \in F$, firm $j$ 's net profits are given by $\pi_{j}\left(B, s^{j}\right)=R^{j}(B)-\sum_{i \in B} s_{i}^{j}$. Each worker $i \in W$ has quasi-linear utility in money and has an integer minimum wage requirement $w_{i}^{j} \geq 0$ for being willing to work at firm $j \in F$. Because of the minimum wage requirement, for the same salary worker $i$ may prefer to be hired by firm $j$ rather than by firm $k$. The integer value assumption of $R^{j}$ and $w_{i}^{j}$ is quite natural and standard, as for example we cannot specify a monetary payoff more closely than to its nearest penny. ${ }^{13}$ The information about $R^{j}$ and $w_{i}^{j}$ can be private, as explained in the next section. We use $\left(F, W,\left(R^{j} \mid j \in F\right),\left(w_{i}^{j} \mid i \in W, j \in F\right)\right)\left(\operatorname{or}\left(F, W, R^{j}, w_{i}^{j}\right)\right.$, in short) to represent this economy. In addition, for any $F^{\prime} \subseteq F$ and $W^{\prime} \subseteq W$, let $\left(F^{\prime}, W^{\prime}, R^{j}, w_{i}^{j}\right)$ be the economy only consisting of firms in $F^{\prime}$ and workers in $W^{\prime}$. In the sequel a worker or firm may be simply called an agent.

A matching $\mu$ in the labor market is a correspondence such that

- for all $i \in W$, either $\mu(i)=i$ or $\mu(i) \in F$,

- for all $j \in F, \mu(j) \subseteq W$, and

- for all $i \in W$ and $j \in F, \mu(i)=j$ if and only if $i \in \mu(j)$.

At matching $\mu$, for any worker $i \in W$, if $\mu(i) \in F$, then $\mu(i)$ represents the firm to which worker $i$ is assigned. If $\mu(i)=i$, then worker $i$ is not assigned to any firm and we will say that such worker $i$ is unemployed or self-matched. For any firm $j \in F, \mu(j)$ stands for the set of workers hired by firm $j$. If $\mu(j)$ is empty, then firm $j$ does not employ any worker.

A salary scheme system $S=\left(s^{j} \mid j \in F\right)$ consists of salary schemes $s^{j} \in \mathbf{R}_{+}^{W}$ of all firms $j \in F$. A state or allocation of the market consists of a salary scheme system $S=\left(s^{j} \mid j \in F\right)$ and a matching $\mu$. At allocation $(\mu, S)$, if $\mu(i)=j \in F$ for any worker $i \in W$, then worker $i$ works for firm $j$ and receives salary $s_{i}^{j}$; if $\mu(i)=i$, then worker $i$ does not work for any firm and receives no salary, and firm $j$ hires the group $\mu(j)$ of workers and pays the total amount $s^{j}(\mu(j))=\sum_{i \in \mu(j)} s_{i}^{j}$ of salary. An allocation $(\mu, S)$ induces a payoff vector

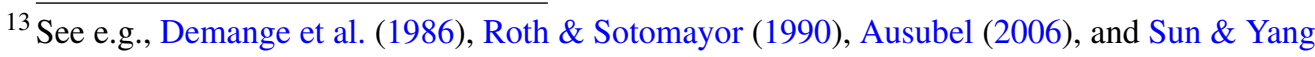
(2009). 
$u \in \mathbf{R}^{F \cup W}$ such that for every worker $i \in W, u_{i}=s_{i}^{\mu(i)}-w_{i}^{\mu(i)}$ when $\mu(i) \in F$, and $u_{i}=0$ when $\mu(i)=i$, and for every firm $j \in F, u_{j}=\pi_{j}\left(\mu(j), s^{j}\right)$. In this way, the state $(\mu, S)$ can be alternatively written as $(\mu, u)$. Observe that at every state $(\mu, u)$ we have $u_{j}+\sum_{i \in \mu(j)} u_{i}=R^{j}(\mu(j))-\sum_{i \in \mu(j)} w_{i}^{j}$ for every firm $j \in F$ and $u_{k}=0$ for every worker $k \in W$ with $\mu(k)=k$.

A state $(\mu, u)$ is individually rational if no agent is worse than she stands alone, i.e., $u_{k} \geq 0$ for every $k \in F \cup W$. A nonempty group $B \subseteq F \cup W$ of workers and firms is called a coalition. Following Kelso \& Crawford (1982, p. 1487), we say that a coalition $B$ is essential if it contains either only one worker or only one firm with any number of workers. (Note that we make this definition slightly more general than theirs by including the case of either a single firm or a single worker to cover individual rationality.) In the following any coalition means an essential coalition. Sometimes it is convenient to use $(j, B)$ to express a coalition in order to distinguish the firm and workers, where $j \in F$ or $j=\emptyset$, and $B \subseteq W$.

A state $(\mu, u)$ is weakly blocked by an individually rational coalition $B \subseteq F \cup W$ (or simply weakly blocked by a coalition) (i) if there exists one firm $j \in B$ with a nonnegative payoff vector $r \in \mathbf{R}_{+}^{B}$ such that

$$
\begin{gathered}
r_{k} \geq u_{k} \text { for every } k \in B, \text { and } \\
\sum_{k \in B} r_{k}=R^{j}(B \backslash\{j\})-\sum_{k \in B \backslash\{j\}} w_{k}^{j}
\end{gathered}
$$

with at least one strict inequality for (1), or (ii) if the coalition $B$ contains only one worker $i$ with $r_{i}=0>u_{i}$. Notice that all members in the coalition $B$ are individually rational, i.e., $r_{k} \geq 0$ for all $k \in B$, and that in case (i), if $B$ contains only a firm $j$, then $r_{j}=0>u_{j}$. The definition says that at least one member in $B$ would be better off and none in $B$ would be worse off if firm $j$ hires only workers $i \in B$ and every worker $i \in B$ works for firm $j$, or it would be strictly better for the single firm not to hire any worker or for the single worker $i$ not to work at firm $\mu(i)$. Such a $B$ is called an individually rational weakly blocking coalition (or simply a weakly blocking coalition). An (individually rational) strongly blocking coalition is defined in the same manner as a weakly blocking coalition, except that (1) is now strengthened as a strict inequality for every member in $B$. Throughout the paper every (weakly or strongly) blocking coalition means an individually rational blocking coalition unless stated otherwise. With respect to a blocking coalition $(j, B)$ of $(\mu, u)$, 
we say that a firm $k(\neq j)$ is deserted if $B$ contains at least one worker from $\mu(k)$, and that a worker $w \in \mu(j)$ is dismissed if $B$ does not contain $w$. A firm $k(\neq j)$ is unaffected if $B$ does not contain any worker from $\mu(k)$.

A state is a core allocation if it is not strongly blocked by any coalition. Clearly, a state is a core allocation if and only if it is individually rational and is not strongly blocked by any firm with at least one worker. A state is a strict core allocation or a competitive equilibrium if it is not weakly blocked by any coalition. ${ }^{14}$ Observe that unemployment is allowed in equilibrium. It is well known from Kelso \& Crawford (1982, p. 1487) that the set of competitive equilibria in this market coincides with the set of strict core allocations. ${ }^{15}$

The following definition describes how the market will transfer from a disequilibrium state to another state through a blocking coalition.

Definition 1 Let $B \subseteq F \cup W$ be a blocking coalition against the state $(\mu, u)$ with the associated payoff vector $r \in \mathbf{R}^{B}$. A new state $\left(\mu^{\prime}, u^{\prime}\right)$ is said to be a coalition improvement of the state $(\mu, u)$ through $B$ with every deserted or unaffected firm maintaining the status quo for its remaining employees (or simply a coalition improvement with the status quo maintaining rule) if the new state is constructed as follows:

(1) if there exists one firm $j \in B$, let

(1a) $\mu^{\prime}(i)=j$ and $u_{i}^{\prime}=r_{i}$ for every worker $i \in B$,

(1b) $\mu^{\prime}(j)=B \backslash\{j\}$ and $u_{j}^{\prime}=r_{j}$,

(1c) $\mu^{\prime}(i)=i$ and $u_{i}^{\prime}=0$ for every worker $i \in \mu(j) \backslash B$,

(1d) $\mu^{\prime}(i)=\mu(i)$ and $u_{i}^{\prime}=u_{i}$ for every worker $i \in W \backslash(B \cup \mu(j))$,

(1e) $\mu^{\prime}(k)=\mu(k) \backslash B$ and

$$
u_{k}^{\prime}=R^{k}(\mu(k) \backslash B)-\sum_{i \in \mu(k) \backslash B}\left(w_{i}^{k}+u_{i}\right)
$$

for every firm $k \in F \backslash\{j\}$; or

\footnotetext{
${ }^{14}$ We point out that in the definition of a blocking coalition we ignore those nonessential blocking coalitions in which some members may have negative payoffs. However, doing so does not lose any generality. See the appendix of this paper for a detailed discussion.

${ }^{15}$ Perry and Reny (1994) provide a noncooperative foundation for this fundamental cooperative solution-the core.
} 
(2) if the coalition B consists of only one worker i, let

(2a) $\mu^{\prime}(i)=i$ and $u_{i}^{\prime}=0$,

(2b) $\mu^{\prime}(k)=\mu(k)$ and $u_{k}^{\prime}=u_{k}$ for every worker $k \in W \backslash\{i\}$,

(2c) $\mu^{\prime}(\mu(i))=\mu(\mu(i)) \backslash\{i\}$ and

$$
u_{\mu(i)}^{\prime}=R^{\mu(i)}(\mu(\mu(i)) \backslash\{i\})-\sum_{k \in \mu(\mu(i)) \backslash\{i\}}\left(w_{k}^{\mu(i)}+u_{k}\right),
$$

(2d) $\mu^{\prime}(k)=\mu(k)$ and $u_{k}^{\prime}=u_{k}$ for every firm $k \in F \backslash\{\mu(i)\}$.

By definition, at the new state $\left(\mu^{\prime}, u^{\prime}\right)$, if $B$ contains a firm $j$, then firm $j$ will hire all workers $i \in B \backslash\{j\}$ and share the revenue according to the given specification $r \in \mathbb{R}^{B}$, whereas workers in $\mu(j)$ not in $B$ will be dismissed by firm $j$ and become unemployed to get a payoff of zero and all other workers outside $B \cup \mu(j)$ will maintain the status quo of $(\mu, u)$. Observe that every firm $k \in F \backslash\{j\}$ will continue to hire those workers who are not in the blocking coalition $B$ and who were hired by firm $k$ at $(\mu, u)$, and that a deserted firm $k$ 's payoff may be negatively affected because firm $k$ will keep the same contract with each of its remaining workers as in the state $(\mu, u)$, and that every unaffected firm and its employees will not be affected and thus preserve the status quo of $(\mu, u)$. With respect to a coalition improvement with the status quo maintaining rule through the blocking coalition $B$, we also distinguish weak coalition improvement from strong coalition improvement, depending on whether the associated blocking coalition $B$ is weak or strong.

The weak coalition improvement with the status quo maintaining rule imitates real life business practices. When a firm and a group of workers find an opportunity to form a weakly blocking coalition, the firm and hired workers are better off but the deserted firms and dismissed workers are usually worse off. Therefore coalition improvements with the status quo maintaining rule are just local not global improvements for the market. In other words, during this process, the overall welfare of the market is not monotonic and can be increasing or decreasing. If an employee leaves a firm for a better offer from another firm, the abandoned firm will usually not change contracts immediately for its remaining employees and needs time to adapt to the new situation. It is fairly common that such a firm will continue to operate for a period of time even if it is in debt. If a worker is fired by a firm, she needs time to find a new job. In such processes, it is not unusual to observe that as in 
reality, a worker may jump from one position to another and may eventually return to her previous employer, but with a different contract. Weak coalition improvements also allow a firm in debt to be adjudicated bankrupt by firing all its employees, or continue to run by taking no action, or reorganize by hiring and firing, as in real life business.

Observe that we define all concepts such as a blocking coalition and a competitive equilibrium on the basis of real numbers. However, most real life market processes work only on rational or integral salaries or prices. The following lemma shows that, assuming integrality of revenue functions and minimum salary requirements, an integral state $(\mu, u)$ is a competitive equilibrium within the domain of real payoffs if (and only if) it is not weakly blocked by any coalition with integral payoffs. It should be noticed that this result holds true without requiring any other extra conditions.

Lemma 1 Let $R^{j}$ and $w_{i}^{j}$ for all $i \in W$ and $j \in F$ be integral. If a state $(\mu, u)$ with $u \in Z^{F \cup W}$ is not weakly blocked by any coalition $B$ with integral payoffs $v_{i} \in \mathrm{Z}$ for all $i \in B$, then it cannot be blocked by any coalition $T$ with real payoffs $u_{i}^{\prime} \in \mathbf{R}$ for all $i \in T$. Consequently, $(\mu, u)$ must be a competitive equilibrium.

Proof. Suppose to the contrary that an integral state $(\mu, u)$ with $u \in Z^{F \cup W}$ which is not blocked by any group of firm $j$ and workers $B$ with integral payoffs $v_{j}, v_{i} \in \mathbb{Z}$ for all $i \in B$, is blocked by a group of firm $k$ and workers $T$ with real payoffs $u_{k}^{\prime}, u_{i}^{\prime} \in \mathbf{R}$ for all $i \in T$. Because the coalition $T \cup\{k\}$ blocks $(\mu, u)$, then we have

$$
\begin{gathered}
u_{k}^{\prime}+\sum_{i \in T} u_{i}^{\prime}=R^{k}(T)-\sum_{i \in T} w_{i}^{k}, \\
u_{k}^{\prime} \geq u_{k} \text { and } u_{i}^{\prime} \geq u_{i} \text { for all } i \in T
\end{gathered}
$$

with at least one strict inequality. Let $K=\left\{i \in T \mid u_{i}^{\prime}>u_{i}\right.$ and $\left.u_{i}^{\prime} \notin \mathbb{Z}\right\} \cup\{k \mid$ $u_{k}^{\prime}>u_{k}$ and $\left.u_{k}^{\prime} \notin \mathrm{Z}\right\}$. If $K$ is empty, we have a contradiction. If $K$ is not empty, it follows from (3) and the integer number $R^{k}(T)-\sum_{i \in T} w_{i}^{k}$ that $K$ contains at least two elements. Take any element $i^{*} \in K$. Then let $\bar{u}_{i}=u_{i}(\in \mathrm{Z})$ for every $i \in K$ with $i \neq i^{*}$ and $\bar{u}_{i}=u_{i}(\in \mathrm{Z})$ for every $i \in(T \cup\{k\}) \backslash K$, and $\bar{u}_{i^{*}}=R^{k}(T)-\sum_{i \in T} w_{i}^{k}-\sum_{i \in(T \cup\{k\}) \backslash\left\{i^{*}\right\}} u_{i}\left(>u_{i^{*}}\right) . \bar{u}_{i^{*}}$ is an integer. Because $u_{i}$ for all $i \in F \cup W, R^{j}$ for all $j \in F$, and $w_{i}^{j}$ for all $j \in F$ and $i \in W$ are integers, we have the coalition $T \cup\{k\}$ with integer payoffs $\bar{u}_{k}$ and $\bar{u}_{i}$ for all $i \in T$ that 
blocks $(\mu, u)$, yielding a contradiction. The case of a singleton coalition is easy to verify. This completes the proof.

For convenience, a state $(\mu, u)$ with an integral payoff vector $u \in Z^{F \cup W}$ or equivalently integral salaries or prices will be called an integral state. We are particularly interested in integral states because transactions in real world business can happen only in integral or rational numbers of monetary units. The above lemma shows that it is sufficient to concentrate on integral states. There are several major sufficient conditions guaranteeing the existence of an integral competitive equilibrium. The most well-known of these conditions is the Gross Substitutes condition of Kelso and Crawford (1982), which will be introduced shortly.

Given a salary scheme $s^{j} \in \mathbf{R}^{W}$, let $D^{j}\left(s^{j}\right)$ be the set of solutions to

$$
\max _{T \subseteq W} \pi_{j}\left(T, s^{j}\right)
$$

$D^{j}\left(s^{j}\right)$ is the collection of those groups of workers which give the firm the highest profit at the offered salaries $s^{j}$.

Definition 2 Firm $j$ satisfies the Gross Substitutes condition if for every pair of salary schemes $s^{j}$ and $t^{j}$ with $s^{j} \leq t^{j}$ and for every $A \in D^{j}\left(s^{j}\right)$, there exists $C \in D^{j}\left(t^{j}\right)$ such that $\left\{i \mid i \in A\right.$ and $\left.s_{i}^{j}=t_{i}^{j}\right\} \subseteq C$.

This condition states that if a firm $j$ hires a group $A$ of workers at salaries $s^{j}$ and if the salaries are now increased to the new levels $t^{j}$, the firm will still want to hire those workers in $A$ whose salaries do not increase.

It is well known that this job matching market admits at least one competitive equilibrium and that the set of strict core allocations coincides with that of competitive equilibria (Kelso \& Crawford (1982)). In addition, as all valuations $w_{i}^{j}$ and $R^{j}$ are integers and every firm satisfies the Gross Substitutes condition, the labour market must have at least one strict core allocation with an integral payoff vector $u \in Z^{F \cup W}$ or an integral salary system $S=\left(s^{1}, s^{2}, \cdots, s^{m}\right) \in Z^{W \times F}$; see Gul \& Stacchetti (1999), Ausubel (2006), and Sun \& Yang (2009). Notice that the celebrated assignment market of Koopmans \& Beckmann (1957) and Shapley \& Shubik (1971) automatically satisfies the Gross Substitutes condition and thus has an integral equilibrium. In the rest of the paper in order to avoid repetition, every (market) state is taken to mean an integral (market) state unless stated otherwise. 


\section{SPONTANEOUS DECENTRALIZED MARKET PROCESSES}

In this section we address the central issue whether a spontaneous decentralized random market process can settle the market in a competitive equilibrium or not. Suppose that the market starts at time 0 with an arbitrary state. It is plausible to assume that information about the market is dispersed among all the market participants and no single agent or organization commands complete knowledge of the market. For instance, each firm $j$ possesses private information about its own revenue function $R^{j}$ and each worker $i$ knows her own minimum wage requirement $w_{i}^{j}$ privately. Because firms and workers are self-interested, any individual or group of agents will be willing to grasp any opportunity to improve their wellbeing by forming a new coalition within which the firm may fire some of its workers and hire some workers from other firms, and some workers may abandon their employers. Deserted firms will at least temporarily maintain the status quo for their remaining employees. The formation of the new coalition is a weak coalition improvement against the current state with the status quo maintaining rule. Because the market is totally decentralized and uncoordinated and agents are not assumed to have complete knowledge of the market, such coalition improvements with the status quo maintaining rule cannot be expected to occur with absolute certainty but with a positive probability. Moreover because real life transactions take place only in an integral number of monetary units, it suffices to work with only integral weak coalition improvements with the status quo maintaining rule. Obviously, this spontaneous decentralized random process will continue to move from one disequilibrium state to another until a competitive equilibrium is reached.

A natural and fundamental question arises here: will such a spontaneous decentralized random market process converge to a competitive equilibrium eventually? The following theorem gives an affirmative answer by showing that this general process will almost surely converge to a competitive equilibrium in finite time, provided that at any point in time, every weak coalition improvement with the status quo maintaining rule conditional on the current market state arises with a positive probability bounded away from zero. The assumption of a positive probability for every weak coalition improvement is intended to capture pervasive uncertainty about opportunities in decentralized and uncoordinated markets. For instance, in academic markets, even a top department with attractive offers cannot guarantee to fill its vacancies. This assumption also implies that although information about the market is dispersed 
among all the agents involved, job-related information flows smoothly enough so that agents can grasp newly arrived opportunities in the market at least with a positive probability.

As it will be clear in the following proof of Theorem 1, the requirement of the positive probability being no less than any fixed small number $\varepsilon>0$ is really minimal. This probability could be viewed as a measure of market transparency. The magnitude of this positive number $\varepsilon$ will not affect the convergence of the decentralized random competitive process but it does have an impact on the convergence speed. In general, the bigger $\varepsilon$ is, the faster the process will be.

Theorem 1 Assume that the labour market $\left(F, W, R^{j}, w_{i}^{j}\right)$ has a competitive equilibrium. Then, starting with an arbitrary market state, any random and decentralized process in which every weak coalition improvement with the status quo maintaining rule occurs with a positive probability conditional on the current state and time bounded away from zero, will converge with probability one to a competitive equilibrium in finite time.

Several remarks are in order. First, the market has an infinite number of (integral) market states amongst which there are only a few equilibrium states and the rest are all disequilibrium states. Each disequilibrium state can be blocked by at least one coalition and is therefore associated with at least one coalition improvement with the status quo maintaining rule. Second, at each disequilibrium state there exists a finite number of coalition improvements with the status quo maintaining rule. Third, as it will be shown in Lemma 2, starting from any given market state, the set of market states that can be generated through all possible successive coalition improvements with the status quo maintaining rule is finite. This means that the assumption of a positive probability in the theorem is actually imposed only upon a finite number of market states which can be historically linked with the initial market state via coalition improvements with the status quo maintaining rule.

Corollary 1 Assume that every firm in the market $\left(F, W, R^{j}, w_{i}^{j}\right)$ satisfies the Gross Substitutes condition. Then, starting with an arbitrary market state, any random and decentralized process in which every weak coalition improvement with the status quo maintaining rule occurs with a positive probability conditional on the current state and time bounded away from zero, converges almost surely to a competitive equilibrium in finite time. 
The proof of the theorem above relies on the following crucial mathematical result, which establishes a link between any initial market state and a competitive equilibrium through only a finite sequence of successive weak coalition improvements with the status quo maintaining rule. The distinguishing feature of finite successive weak coalition improvements with the status quo maintaining rule is essential to capture the decentralized nature of the random market process. Any other path which does not exhibit this feature but may still connect the initial market state with a competitive equilibrium will not achieve the goal. It is also worth pointing out that the proof of Theorem 1 depends critically on the statement of Theorem 2 but not on its proof technique or procedure.

Theorem 2 Assume that the labour market $\left(F, W, R^{j}, w_{i}^{j}\right)$ has a competitive equilibrium. Then there exists a finite number of successive weak coalition improvements with the status quo maintaining rule linking an arbitrary market state with a competitive equilibrium.

We now discuss how to establish Theorem 1 via Theorem 2. As pointed out in the previous section, it is sufficient and also natural to confine ourselves to integral market states. We first demonstrate the following lemma, which provides an important insight into the spontaneous market process under examination, i.e., starting from any initial market state, the number of market states that can be possibly generated by successive coalition improvements with the status quo maintaining rule is finite.

Lemma 2 For any given initial market state $\left(\mu^{0}, u^{0}\right)$, the set $A\left(\mu^{0}, u^{0}\right)$ of all market states that can be attained through successive coalition improvements with the status quo maintaining rule is finite.

Proof. Consider an arbitrary firm $j \in F$. Let $S(j, 0)$ be the total salaries that firm $j$ paid to its employees $\mu^{0}(j)$ at the initial market state $\left(\mu^{0}, u^{0}\right)$. Let $M=\max _{j \in F} R^{j}(W)$ be the maximum among all firms' revenues. Let $\left(\mu^{t}, u^{t}\right)$, $t=0,1,2, \cdots$, be any sequence of states that begins with $\left(\mu^{0}, u^{0}\right)$ and can be possibly generated through coalition improvements with the status quo maintaining rule. Observe that this process moves from one disequilibrium $\left(\mu^{t}, u^{t}\right)$ to another state $\left(\mu^{t+1}, u^{t+1}\right)$, because a coalition $\left(j^{t}, B^{t}\right)$ weakly blocks the state $\left(\mu^{t}, u^{t}\right)$, where $j^{t} \in F$ or $j^{t}=\emptyset$ and $B^{t} \subseteq W$. Now we prove that the payoff of every agent $k \in F \cup W$ is bounded at any time. By coalition 
improvement with the status quo maintaining rule (Definition 1), as long as any firm $j$ is deserted or unaffected, its net profit cannot be less than $-S(j, 0)-1$ $\left(<R^{j}(\emptyset)-S(j, 0)=-S(j, 0)\right.$ which is the worst case for firm $j$ that still pays $S(j, 0)$ but receives no revenue). When any firm $j$ emerges in a blocking coalition, its net profit will be weakly increasing and cannot be below zero, and after such adjustments even when it becomes deserted or unaffected or emerges in a blocking coalition again and again, its net profit cannot be less than $-R^{j}(W)$, because firm $j$ will never pay more than $R^{j}(W)$ for any group of workers. Firm $j^{\prime}$ s net profit is equal to $R^{j}(T)-\sum_{i \in T} s_{i}^{j, t}$, where $T$ is the group of workers hired by firm $j$ at time $t$ and $\sum_{i \in T} s_{i}^{j, t}$ is the salaries paid by firm $j$ at time $t$. Obviously, firm $j^{\prime}$ s net profit can never be above $R^{j}(W)$. Thus firm $j^{\prime}$ s payoff is always between $-\min \left\{R^{j}(W), S(j, 0)+1\right\}$ and $R^{j}(W)$. Every worker $i^{\prime}$ s payoff is clearly between $\min \left\{0, u_{i}^{0}\right\}$ and $M$, and therefore is also bounded. This shows that the sequence $\left(\mu^{t}, u^{t}\right), t=0,1,2, \cdots$, is bounded. Observe that the bounded set $A\left(\mu^{0}, u^{0}\right)$ is finite, because every state is integral and the number of matchings is finite.

It may be obvious but important to note that starting from any point in the set $A\left(\mu^{0}, u^{0}\right)$, any sequence of market states that can be generated through coalition improvements with the status quo maintaining rule lies also in the set $A\left(\mu^{0}, u^{0}\right)$.

We are now ready to prove Theorem 1 . Suppose that the market starts with the initial market state $\left(\mu^{0}, u^{0}\right)$ and operates at discrete time $t=1,2, \cdots$. Consider a general decentralized random market process in which every timedependent transition probability from a disequilibrium state in $A\left(\mu^{0}, u^{0}\right)$ at any time $t$ to another state in $A\left(\mu^{0}, u^{0}\right)$ at time $t+1$ is no less than a fixed (but sufficiently small) number $\varepsilon \in(0,1)$, namely, every possible weak coalition improvement with the status quo maintaining rule occurs with a positive probability bounded away from zero. With only two classes of states (equilibrium and disequilibrium), it follows that starting from any state $(\mu, u)$ in $A\left(\mu^{0}, u^{0}\right)$, the process either terminates in an equilibrium state and remains in equilibrium afterwards, or continues to move from one disequilibrium state to another disequilibrium state in $A\left(\mu^{0}, u^{0}\right)$, as the random process by construction always arrives at a state in $A\left(\mu^{0}, u^{0}\right)$. Suppose that the random process does not converge to an equilibrium state with probability one in the limit. This implies that, starting from a disequilibrium state in $A\left(\mu^{0}, u^{0}\right)$, the random process almost surely moves around within a (finite) set of disequilibrium states in 
$A\left(\mu^{0}, u^{0}\right)$ forever and therefore some of these disequilibrium states could be visited an infinite number of times. Since each possible weak coalition improvement with the status quo maintaining rule is chosen with a probability no less than $\varepsilon$ at each point of time, there is then some state $\left(\mu^{\prime}, u^{\prime}\right)$ in $A\left(\mu^{0}, u^{0}\right)$ from which no finite path of weak coalition improvements with the status quo maintaining rule toward equilibrium exists, no matter how the associated weak coalition improvements are chosen, yielding a contradiction to Theorem 2. This completes the proof of Theorem 1.

\section{THE EXISTENCE OF A DESIRED PATH TO EQUILIBRIUM}

We will prove Theorem 2 in this section. The main difficulty is to show the existence of a finite sequence of successive weak coalition improvements with the status quo maintaining rule linking an arbitrary initial integral market state with a competitive equilibrium. This sequence is our desired path and any other path which does not generate successive weak coalition improvements with the status quo maintaining rule but still leads to a competitive equilibrium will not help to establish the theorem.

Because the labor market $\left(F, W, R^{j}, w_{i}^{j}\right)$ is assumed to have a competitive equilibrium with integral equilibrium payoffs, we can regard any such competitive equilibrium $\left(\mu^{*}, u^{*}\right)$ as a reference equilibrium point. The idea of using a reference point is a conventional thought experiment method and can avoid many practical issues and has been used in theoretical physics. Biró et al. (2014) apply this idea to the unit-demand models such as roommate matching and assignment problems. For our purpose, the real challenge lies in how to construct a desired path from any initial state to a competitive equilibrium by using a reference point. It is, however, insufficient to just construct $a$ path from any initial state to a competitive equilibrium by using a reference point without requiring that the path should be a path of successive weak coalition improvements with the status quo maintaining rule. It is also worth pointing out that our method of constructing a desired path is very general in the sense that it works for any market as long as the market has an equilibrium. We will use the reference $\left(\mu^{*}, u^{*}\right)$ and an arbitrary initial market state $(\mu, u)$ to construct a desired path, denoted by $P\left(\left(\mu^{*}, u^{*}\right),(\mu, u)\right)$. The path $P\left(\left(\mu^{*}, u^{*}\right),(\mu, u)\right)$ thus exists and can be seen as a function of the reference point and the initial state. Thus the reference point plays a role as a variable, which means that we do not need to know any specific or precise reference point in order to establish the 
existence of a desired path from any initial state to a competitive equilibrium. This thought experiment method serves the purpose of proving Theorem 2 but is not a practical economic adjustment process.

Given a state $(\mu, u)$, an agent $i \in F \cup W$ is underpaid (overpaid) at $(\mu, u)$ with respect to the reference point $\left(\mu^{*}, u^{*}\right)$ if $u_{i} \leq u_{i}^{*}\left(u_{i}>u_{i}^{*}\right)$. Given any $U \subseteq W$ and $j \in F$, we define $u(U)=\sum_{i \in U} u_{i}$ and $w^{j}(U)=\sum_{i \in U} w_{i}^{j}$. For convenience we also use $\pi_{j}$ to stand for the payoff $u_{j}$ of firm $j \in F$ in a state $(\mu, u)$.

We will describe a general procedure that, starting from any initial market state $(\mu, u)$, generates a finite number of weak coalition improvements with the status quo maintaining rule leading to a competitive equilibrium. We first give a subroutine UPDATE which will be repeatedly used in the procedure.

The subroutine UPDATE tells us how to adjust a state $(\mu, u)$ weakly blocked by the coalition $(j, U)$ to a new state $\left(\mu^{\prime}, u^{\prime}\right)$. It specifies one type of weak coalition improvement with the status quo maintaining rule.

\section{$\operatorname{UPDATE}(\mu, u, j, U)$}

(a) Start from an integral market state $(\mu, u)$ weakly blocked by $(j, U)$. Go to Step (b).

(b) If $j=\emptyset$, go to Step (e). If $j \in F$, let $F^{\prime}=\{k \in F \backslash\{j\} \mid \mu(k) \cap U \neq \emptyset\}$ and $F^{*}=\{k \in F \backslash\{j\} \mid \mu(k) \cap U=\emptyset\}$. Make workers in $\mu(j) \backslash U$ unemployed and their payoffs at zero, i.e., let $\mu^{\prime}(i)=i$ and $u_{i}^{\prime}=0$ for every $i \in \mu(j) \backslash U$. Firm $j$ hires all workers in $U$, i.e., let $\mu^{\prime}(j)=U$. Go to Step (c).

(c) If there exists an overpaid worker $i \in U$, then increase one such $u_{i}^{\prime}$ so that

$$
u_{i}^{\prime}+\sum_{l \in U \backslash\{i\}} u_{l}=R^{j}(U)-\pi_{j}-w^{j}(U),
$$

let $u_{l}^{\prime}=u_{l}$ for every $l \in U \backslash\{i\}$ and $\pi_{j}^{\prime}=\pi_{j}$, and then go to Step (e). Otherwise, go to Step (d).

(d) There exists no overpaid worker in $U$. Increase all underpaid workers' $u_{i}^{\prime}$ as much as possible in such a way that $u_{i}^{\prime} \leq u_{i}^{*}$ with $u_{i}^{\prime} \in \mathrm{Z}$ and $u^{\prime}(U) \leq$ $R^{j}(U)-\pi_{j}-w^{j}(U)$. If $u^{\prime}(U)=R^{j}(U)-\pi_{j}-w^{j}(U)$, let $\pi_{j}^{\prime}=\pi_{j}$ and go to Step (e). Otherwise let $\pi_{j}^{\prime}=R^{j}(U)-u^{\prime}(U)-w^{j}(U)$ and go to Step (e). 
(e) For each $k \in F^{\prime}$, let $U_{k}=\mu(k) \backslash U$. Every firm $k \in F^{\prime}$ continues to hire all remaining workers in $U_{k}$ under the same contract as in $(\mu, u)$, and adjusts its net profit, i.e., let $u_{i}^{\prime}=u_{i}$ for every $i \in U_{k}, \mu^{\prime}(k)=U_{k}$ and $\pi_{k}^{\prime}=R^{k}\left(U_{k}\right)-u\left(U_{k}\right)-w^{k}\left(U_{k}\right)$. For each $k \in F^{*}$, let $\pi_{k}^{\prime}=\pi_{k}$ and $u_{i}^{\prime}=u_{i}$ for every $i \in \mu(k)$. Go to Step (f).

(f) Set $(\mu, u)=\left(\mu^{\prime}, u^{\prime}\right)$ and get a new integral market state $(\mu, u)$.

The process comprising Steps (a), (b), (c) and (d) is called $\operatorname{Reshuffle}(\mu, u, j, U)$ while the process consisting of only Step (e) is called $\operatorname{Retention}(\mu, u, j, U)$.

If a state $(\mu, u)$ is weakly blocked by a coalition $(j, U)$ with $j \in F$ and $U \subseteq W$, by definition we have

$$
R^{j}(U)-w^{j}(U)>\pi_{j}+u(U) .
$$

Since $\left(\mu^{*}, u^{*}\right)$ is a competitive equilibrium, it follows that

$$
\pi_{j}^{*}+u^{*}(U) \geq R^{j}(U)-w^{j}(U)>\pi_{j}+u(U) .
$$

This implies that UPDATE can be executed.

Lemma 3 After UPDATE, if firm j's payoff $\pi_{j}^{\prime}$ increases, we have $u_{i}^{\prime}=u_{i}^{*}$ for all $i \in U$ and also $\pi_{j}^{\prime} \leq \pi_{j}^{*}$.

Proof. Note that $\pi_{j}^{\prime}$ gets increased only if Step (d) is executed, i.e., $\pi_{j}^{\prime}=$ $R^{j}(U)-u^{\prime}(U)-w^{j}(U)$ and $u_{i}^{\prime}=u_{i}$ for all $i \in U$. Since $\pi_{j}^{\prime}+u^{*}(U)=\pi_{j}^{\prime}+$ $u^{\prime}(U)=R^{j}(U)-w^{j}(U) \leq \pi_{j}^{*}+u^{*}(U)$, we have $\pi_{j}^{\prime} \leq \pi_{j}^{*}$.

Note that if $U$ contains at least one overpaid worker, after the execution of UPDATE firm $j$ 's payoff remains the same as in the state $(\mu, u)$.

We are now ready to describe the procedure which, starting from an arbitrary integral market state, will generate a finite sequence of successive coalition improvements with the status quo maintaining rule leading to a competitive equilibrium.

\section{The Procedure for Constructing a Desired Path to Equilibrium}

Step 0 Let $\left(\mu^{*}, u^{*}\right)$ be a reference equilibrium of the market. Start with an arbitrary integral market state $(\mu, u)$. Go to Step 1 . 
Step 1 If there exists a weakly blocking coalition $(j, U)$ with $j \in F$ and $U \subseteq$ $\mu(j) \cup \mu^{*}(j)$ against the current state $(\mu, u)$, choose one such $j$ and go to Step 2. Otherwise, go to Step 3.

Step 2 Find an optimal solution $U^{*}$ to the following problem

$$
\begin{array}{cl}
\max & R^{j}(X)-u(X)-w^{j}(X) \\
\text { s.t. } & X \subseteq \mu(j) \cup \mu^{*}(j) .
\end{array}
$$

Perform UPDATE $\left(\mu, u, j, U^{*}\right)$ and get a new state $(\mu, u)$. Go to Step 1 .

Step 3 If the state $(\mu, u)$ is weakly blocked by a coalition $(j, U)$, perform $\operatorname{UPDATE}(\mu, u, j, U)$ by giving a new state $(\mu, u)$ and go to Step 1 . Otherwise stop with the current state $(\mu, u)$, which is a competitive equilibrium.

For convenience, the process that the Procedure from Step 0 goes through Step 1 and Step 2 before moving into Step 3 is called Phase 1, while the process that the Procedure from the beginning of Step 3 goes through Step 3 before returning to Step 1 is called Phase 2.

The following observation is simple but crucial to the convergence of the Procedure and follows immediately from the construction of the UPDATE process.

Observation 1: In the entire Procedure, every underpaid worker will always remain underpaid. If an overpaid worker becomes underpaid, she will remain underpaid afterwards.

Before proving the convergence of the procedure it is helpful to demonstrate how the procedure works by an example.

An Illustrative Example: Suppose that in a market, there are three firms $f_{1}$, $f_{2}, f_{3}$ and four workers $w_{1}, w_{2}, w_{3}$, and $w_{4}$. Every worker $i$ 's minimum wage $w_{i}^{j}$ equals zero for all firms $j$. Every firm's value over each group of workers is given in Table 1 . Notice that in the table, $w_{12}$ means the group of workers $\left\{w_{1}, w_{2}\right\}$.

It is easy to verify that although this market does not satisfy any known condition imposed on each individual such as the Gross Substitutes condition of Kelso \& Crawford (1982), it does have a unique efficient matching $\mu^{*}$ which 
Table 1: Firms' values over each group of workers.

\begin{tabular}{|c|c|c|c|c|c|c|c|}
\hline & $w_{1}$ & $w_{2}$ & $w_{3}$ & $w_{4}$ & $w_{12}$ & $w_{13}$ & $w_{14}$ \\
\hline$f_{1}$ & 2 & 2 & 1 & 1 & 7 & 3 & 2 \\
\hline$f_{2}$ & 2 & 2 & 7 & 1 & 3 & 7 & 3 \\
\hline$f_{3}$ & 2 & 2 & 2 & 6 & 5 & 3 & 7 \\
\hline & $w_{23}$ & $w_{24}$ & $w_{34}$ & $w_{123}$ & $w_{124}$ & $w_{234}$ & $w_{1234}$ \\
\hline$f_{1}$ & 4 & 3 & 2 & 7 & 7 & 4 & 9 \\
\hline$f_{2}$ & 7 & 2 & 7 & 7 & 3 & 7 & 10 \\
\hline$f_{3}$ & 3 & 6 & 7 & 6 & 7 & 7 & 8 \\
\hline
\end{tabular}

is supported by many competitive equilibrium price vectors, where $\mu^{*}\left(f_{1}\right)=$ $\left\{w_{1}, w_{2}\right\}, \mu^{*}\left(f_{2}\right)=\left\{w_{3}\right\}, \mu^{*}\left(f_{3}\right)=\left\{w_{4}\right\}, \mu^{*}\left(w_{1}\right)=\mu^{*}\left(w_{2}\right)=f_{1}, \mu^{*}\left(w_{3}\right)=$ $f_{2}$, and $\mu^{*}\left(w_{4}\right)=f_{3}$. We will take $\left(\mu^{*}, u^{*}\right)$ as a reference equilibrium with $u_{f_{1}}^{*}=1, u_{f_{2}}^{*}=4$, and $u_{f_{3}}^{*}=u_{w_{1}}^{*}=u_{w_{2}}^{*}=u_{w_{3}}^{*}=u_{w_{4}}^{*}=3$, or $s^{j}=(3,3,3,3)$ for $j=1,2,3$.

In Table 2 we show how a desired path is generated by the procedure. The procedure starts with the state $\left(\mu^{0}, u^{0}\right)$ and ends up with an equilibrium state $\left(\mu^{5}, u^{5}\right)=\left(\mu^{*}, u^{*}\right)$. Note that in Table 2 'opt' means 'optimal', 'state' means 'market state' and 'coalition' means 'weakly blocking coalition'. For each matching $\mu^{k}$ we only write down the group of workers hired by each firm. For instance, $\mu^{1}=\left(w_{12}, \emptyset, \emptyset\right)$ means that firm 1 hires workers $w_{1}$ and $w_{2}$, and firms 2 and 3 hire no worker, and workers 3 and 4 are unemployed. For each payoff vector $u^{k}$, its first three components indicate the payoff of the three firms respectively while its last four components specify the payoff of the four workers respectively. In the table $\left(f_{1}, w_{12}\right)$ is a blocking coalition of $\left(\mu^{0}, u^{0}\right)$, and $\left(\mu^{1}, u^{1}\right)$ is the coalition improvement with the status quo maintaining rule of $\left(\mu^{0}, u^{0}\right)$ through $\left(f_{1}, w_{12}\right)$. Initially, at $\left(\mu^{0}, u^{0}\right)$ worker 2 is overpaid but workers 1, 3 and 4 are underpaid. Observe that in the entire process an underpaid worker will always remain underpaid, and an overpaid worker may become underpaid and thereafter will always be underpaid.

Lemma 4 Let $(\mu, u)$ be the current state of the market with which Step 3 of the Procedure begins. Then for all $j \in F, \mu(j)$ is a maximizer of $R^{j}(X)-$ $u(X)-w^{j}(X)$ in $X \subseteq \mu(j) \cup \mu^{*}(j)$ and there exists no subset $X$ of the set $\mu(j) \cup \mu^{*}(j)$ such that $(j, X)$ weakly blocks $(\mu, u)$. 
Table 2: A desired path generated by the procedure.

\begin{tabular}{|r|c|c|c|c|}
\hline state & coalition & opt $U^{*}$ & matching & payoff \\
\hline$\left(\mu^{0}, u^{0}\right)$ & $\left(f_{1}, w_{12}\right)$ & $\left\{w_{12}\right\}$ & $\mu^{0}=\left(w_{1234}, \emptyset, \emptyset\right)$ & $u^{0}=(0,0,0,1,4,2,2)$ \\
\hline$\left(\mu^{1}, u^{1}\right)$ & $\left(f_{2}, w_{3}\right)$ & $\left\{w_{3}\right\}$ & $\mu^{1}=\left(w_{12}, \emptyset, \emptyset\right)$ & $u^{1}=(0,0,0,1,6,0,0)$ \\
\hline$\left(\mu^{2}, u^{2}\right)$ & $\left(f_{3}, w_{4}\right)$ & $\left\{w_{4}\right\}$ & $\mu^{2}=\left(w_{12}, w_{3}, \emptyset\right)$ & $u^{2}=(0,4,0,1,6,3,0)$ \\
\hline$\left(\mu^{3}, u^{3}\right)$ & $\left(f_{1}, w_{1}\right)$ & $\left\{w_{1}\right\}$ & $\mu^{3}=\left(w_{12}, w_{3}, w_{4}\right)$ & $u^{3}=(0,4,3,1,6,3,3)$ \\
\hline$\left(\mu^{4}, u^{4}\right)$ & $\left(f_{1}, w_{2}\right)$ & $\left\{w_{12}\right\}$ & $\mu^{4}=\left(w_{1}, w_{3}, w_{4}\right)$ & $u^{4}=(0,4,3,2,0,3,3)$ \\
\hline$\left(\mu^{5}, u^{5}\right)$ & & & $\mu^{5}=\left(w_{12}, w_{3}, w_{4}\right)$ & $u^{5}=(1,4,3,3,3,3,3)$ \\
\hline
\end{tabular}

Proof. By Step 2 and UPDATE, for every $j \in F, \mu(j)$ is a maximizer of $R^{j}(X)-u(X)-w^{j}(X)$ in $X \subseteq \mu(j) \cup \mu^{*}(j)$. Hence,

$$
\pi_{j}=R^{j}(\mu(j))-u(\mu(j))-w^{j}(\mu(j)) \geq R^{j}(X)-u(X)-w^{j}(X),
$$

for all $X \subseteq \mu(j) \cup \mu^{*}(j)$. It follows that there exists no $X \subseteq \mu(j) \cup \mu^{*}(j)$ such that $(j, X)$ weakly blocks $(\mu, u)$.

Lemma 5 Every worker $i \in \mu(j) \backslash\left(U^{*} \cup \mu^{*}(j)\right)$ that leaves firm $j$ in Step 2 of the Procedure will never return to the firm afterward before the Procedure goes to Step 3.

Proof. Each worker $i \in \mu(j) \backslash\left(U^{*} \cup \mu^{*}(j)\right)$ before the UPDATE in Step 2 becomes self-employed and disappears from $\mu(j) \cup \mu^{*}(j)$ for the new $\mu(j)$ after the UPDATE in Step 2. Since during the repetition of Step 1 and Step 2 sets $\mu(j) \cup \mu^{*}(j)$ for all $j \in F$ do not get enlarged, such a worker $i$ remains unemployed before Step 3 is invoked.

Lemma 6 Every worker $i \in\left(\cup_{k \in F \backslash\{j\}} \mu(k)\right) \cap U^{*}$ that moves to firm $j$ in Step 2 of the Procedure will never return to her previous firm afterward (but possibly becomes unemployed by being fired by firm $j$ ) before the Procedure goes to Step 3.

Proof. Similarly to the proof of the previous lemma, it follows from the definition of the UPDATE process. 
Observe that every worker $i \in\left(\mu(j) \cap \mu^{*}(j)\right) \backslash U^{*}$ gets $u_{i}=0$ and this will remain the same afterward before the Procedure goes to Step 3. Also note that if the set $\mu(j) \cup \mu^{*}(j)$ remains the same after UPDATE, i.e., only some workers in $\mu(j) \cap \mu^{*}(j)$ leave firm $j$, there is no weakly blocking coalition $(j, U)$ with $U \subseteq \mu(j) \cup \mu^{*}(j)$ after the UPDATE, which can be shown by argument as similar to the proof of Lemma 4.

Lemma 7 Let $(\mu, u)$ be the current state of the market with which Step 3 of the Procedure begins. Then it holds

$$
\pi_{j}^{*}+u^{*}\left(\mu^{*}(j)\right)=\pi_{j}^{*}+u^{*}(\mu(j))=\pi_{j}+u\left(\mu^{*}(j)\right)=\pi_{j}+u(\mu(j))
$$

for all $j \in F$.

Proof. It follows from Lemma 4 that for every firm $j \in F$

$$
\begin{aligned}
\pi_{j}^{*}+u^{*}\left(\mu^{*}(j)\right) & =R^{j}\left(\mu^{*}(j)\right)-w^{j}\left(\mu^{*}(j)\right) \\
& \leq R^{j}(\mu(j))-u(\mu(j))-w^{j}(\mu(j))+u\left(\mu^{*}(j)\right) \\
& =\pi_{j}+u\left(\mu^{*}(j)\right) .
\end{aligned}
$$

On the other hand, since $\left(\mu^{*}, u^{*}\right)$ is a competitive equilibrium, we have for all $j \in F$

$$
\begin{aligned}
\pi_{j}^{*}+u^{*}(\mu(j)) & \geq R^{j}(\mu(j))-w^{j}(\mu(j)) \\
& =\pi_{j}+u(\mu(j)) .
\end{aligned}
$$

It follows from (6) and (7) that

$$
\begin{aligned}
\sum_{j \in F}\left(\pi_{j}+u(\mu(j))\right) & \leq \sum_{j \in F}\left(\pi_{j}^{*}+u^{*}(\mu(j))\right) \\
& \leq \sum_{j \in F}\left(\pi_{j}^{*}+u^{*}\left(\mu^{*}(j)\right)\right) \\
& \leq \sum_{j \in F}\left(\pi_{j}+u\left(\mu^{*}(j)\right)\right) \\
& \leq \sum_{j \in F}\left(\pi_{j}+u(\mu(j))\right) .
\end{aligned}
$$

Hence every inequality in (6)-(8) hold with equality. This leads to $\pi_{j}^{*}+u^{*}\left(\mu^{*}(j)\right)=\pi_{j}^{*}+u^{*}(\mu(j))=\pi_{j}+u\left(\mu^{*}(j)\right)=\pi_{j}+u(\mu(j))$ for all $j \in F$. 
The above proof and lemma also imply the following result.

Lemma 8 Let $(\mu, u)$ be the current state of the market with which Step 3 of the Procedure begins. Then it holds that

$$
u_{i}=0 \text { for all } i \in W \backslash \bigcup_{j \in F} \mu^{*}(j) \text { and } u_{i}^{*}=0 \text { for all } i \in W \backslash \bigcup_{j \in F} \mu(j) \text {. }
$$

Now, we examine the behavior of Step 3 of the Procedure. Take any weakly blocking coalition $(j, U)$ and define $F^{\prime}=\{k \in F \mid U \cap \mu(k) \neq \emptyset\}$. Because of the definitions of $(j, U)$ and $\left(\mu^{*}, u^{*}\right)$ we have

$$
\pi_{j}+u(U)<R^{j}(U)-w^{j}(U) \leq \pi_{j}^{*}+u^{*}(U) .
$$

If $j \notin F^{\prime}$, let $F^{\prime}=F^{\prime} \cup\{j\}$. Then from (5) we have

$$
\begin{aligned}
& \sum_{k \in F^{\prime}}\left(\pi_{k}+u(\mu(k))\right) \\
& =\sum_{k \in F^{\prime} \backslash\{j\}}\left(\pi_{k}+u(\mu(k) \backslash U)\right)+u(\mu(j) \backslash U)+\left(\pi_{j}+u(U)\right) \\
& =\sum_{k \in F^{\prime}}\left(\pi_{k}^{*}+u^{*}(\mu(k))\right) .
\end{aligned}
$$

It follows from (9) and (10) that for some firm $k \in F^{\prime} \backslash\{j\}$

$$
\pi_{k}+u(\mu(k) \backslash U)>\pi_{k}^{*}+u^{*}(\mu(k) \backslash U)
$$

or

$$
u(\mu(j) \backslash U)>u^{*}(\mu(j) \backslash U) .
$$

Case (I): (11) holds. It follows from (11) and the equilibrium $\left(\mu^{*}, u^{*}\right)$ that we have

$$
\pi_{k}+u(\mu(k) \backslash U)>\pi_{k}^{*}+u^{*}(\mu(k) \backslash U) \geq R^{k}(\mu(k) \backslash U)-w^{k}(\mu(k) \backslash U) .
$$

Then by Step (e) of UPDATE we have

$$
\pi_{k}^{\prime}=R^{k}(\mu(k) \backslash U)-w^{k}(\mu(k) \backslash U)-u(\mu(k) \backslash U) .
$$

Hence $\pi_{k}^{\prime}$, the new $\pi_{k}$, strictly decreases compared with previous $\pi_{k}$ in (13). 
Case (II): (12) holds. Then there exists at least one overpaid worker in $\mu(j) \backslash U$. By Step (b) of UPDATE all workers $i \in \mu(j) \backslash U$ become unemployed and at least one overpaid worker in $\mu(j) \backslash U$ becomes underpaid.

We can now establish the following major convergence result of this section and thus prove Theorem 2 .

Theorem 3 The Procedure generates a finite sequence of weak coalition improvements with the status quo maintaining rule leading to a competitive equilibrium.

Proof. Recall that the number of integral feasible market states in $A\left(\mu^{0}, u^{0}\right)$ with the initial allocation $\left(\mu^{0}, u^{0}\right)$ is finite, due to Lemma 2. Furthermore, every market state generated by the Procedure is an integral feasible state satisfying (**) because of Step 2 and Step 3 of the Procedure. If the Procedure does not produce a finite sequence of weak coalition improvements with the status quo maintaining rule leading to a competitive equilibrium, it must yield a finite cycle. The Procedure would repeat the cycle forever. Without loss of generality we assume that at least one Phase $\mathbf{1}$ is executed before the Procedure reaches the cycle.

Notice that Case (II) in Phase 2 never occurs along the cycle, because there are at most $n$ overpaid workers and if any overpaid worker becomes unemployed, it will remain underpaid forever by Observation 1. Thus only Case (I) may occur in Phase 2 along the cycle. Then, since in Case (I) $\pi_{k}$ strictly decreases, $\pi_{k}$ should be increased to recover the loss along the cycle, which can only be done by $\operatorname{Reshuffle}(\mu, u, k, U)$ in Phase 1 when $U(=$ $\mu(k)$ later) does not contain any overpaid workers. Note that each Retention in Phase 1 makes the value of $\pi_{k}$ less than or equal to that of $\pi_{k}$ given at the end of the previous Phase 1, since at the end of Phase 1 then obtained $\mu(k)$ for every $k \in F$ is a maximizer obtained in Step 2, so that removing some workers from $\mu(k)$ results in a lower revenue than that given at the end of the previous Phase 1 for firm $k$, while Retention in Phase $\mathbf{2}$ may only reduce $\pi_{k}$ because of the same reason. Also note that after the Reshuffle $(\mu, u, k, U)$ we have $\pi_{k} \leq \pi_{k}^{*}$ due to Lemma 3 and comments right after that and then keep $\pi_{k} \leq \pi_{k}^{*}$ thereafter. On the other hand, if $\pi_{k} \leq \pi_{k}^{*}$, then because of (11) in Case (I) in Phase 2 there must be at least one overpaid worker in $\mu(k) \backslash U$, where we update $\mu(k)$ by setting $\mu(k)=\mu(k) \backslash U$. Hence along the cycle there exists at least one overpaid worker $i$ who becomes unemployed and thus remains underpaid thereafter forever by Observation 1. But this is impossible along the 
cycle, because there are only at most $n$ overpaid workers. In other words, there will be no overpaid worker along the cycle, yielding a contradiction. Hence the Procedure terminates (in a finite number of successive integral weak coalition improvements with the status quo maintaining rule) with a final integral state $(\mu, u)$ that has no integral weak blocking, which is a competitive equilibrium due to Lemma 1.

It should be noted that the above proof implies that if there exists a competitive equilibrium, then for every initial state $\left(\mu^{0}, u^{0}\right)$ there also exists a competitive equilibrium within $A\left(\mu^{0}, u^{0}\right)$.

\section{THE BENCHMARK CASE OF GROSS SUBSTITUTES}

Weak coalition improvements with the status quo maintaining rule cover all kinds of hiring and firing procedures and some of these procedures could be too general and too complicated for firms to handle, for instance, in practice sometimes it can be very difficult and even controversial for a firm to dismiss a large number of employees at one time. However, under the Gross Substitutes condition it is possible to obtain the following much easier, more intuitive and more well-behaved form of hiring and firing procedure.

A weakly blocking coalition $(j, B)$ against a state $(\mu, u)$ is called a basic weakly blocking coalition if $j=\emptyset$ or if $j \in F$ and one of the following holds:

(1) $B=\mu(j) \cup\{k\}$ for $k \in W \backslash \mu(j)$;

(2) $B=(\mu(j) \cup\{l\}) \backslash\{k\}$ for some worker $k \in \mu(j)$ and some worker $l \in W \backslash \mu(j)$;

(3) $B=\mu(j) \backslash\{k\}$ for some worker $k \in \mu(j)$.

A weak coalition improvement with the status quo maintaining rule $\left(\mu^{\prime}, u^{\prime}\right)$ of $(\mu, u)$ through $(j, B)$ is called a basic weak coalition improvement with the status quo maintaining rule if $(j, B)$ is a basic weakly blocking coalition. With respect to $(j, B)$, in Case (1), firm $j$ hires a new worker, in Case (2), firm $j$ simultaneously dismisses a worker and hires a new worker, and in Case (3), firm $j$ fires a worker.

It is immediately clear that a basic weakly blocking coalition $(j, B)$ against a state $(\mu, u)$ occurs if and only if $j=\emptyset$ or if $j \in F$ and one of the following occurs: 
(1) For a firm $j \in F$ and a worker $k \in W \backslash \mu(j)$,

$$
u_{j}+\sum_{i \in \mu(j)}\left(u_{i}+w_{i}^{j}\right)+u(k)+w_{k}^{j}<R^{j}(\mu(j) \cup\{k\}) .
$$

(2) For a firm $j \in F$, a worker $k \in W \backslash \mu(j)$, and a worker $l \in \mu(j)$,

$$
u_{j}+\sum_{i \in \mu(j) \backslash\{l\}}\left(u_{i}+w_{i}^{j}\right)+u(k)+w_{k}^{j}<R^{j}((\mu(j) \cup\{k\}) \backslash\{l\}) .
$$

(3) For a firm $j \in F$ and a worker $k \in \mu(j)$,

$$
u_{j}+\sum_{i \in \mu(j) \backslash\{k\}}\left(u_{i}+w_{i}^{j}\right)<R^{j}(\mu(j) \backslash\{k\}) .
$$

The following important characterization is called the Single Improvement (SI) property and shown by Gul \& Stacchetti $(1999,2000)$ to be equivalent to the Gross Substitutes condition of Kelso \& Crawford (1982).

Definition 3 Firm $j$ satisfies the Single Improvement property if for every salary scheme $s^{j}$ and $A \notin D^{j}\left(s^{j}\right)$, there exists $B \in D^{j}\left(s^{j}\right)$ such that $R^{j}(B)-$ $\sum_{i \in B} s_{i}^{j}>R^{j}(A)-\sum_{i \in A} s_{i}^{j},|A \backslash B| \leq 1$ and $|B \backslash A| \leq 1$.

Next we show that under the Gross Substitutes condition it is indeed sufficient to consider only basic weakly blocking coalitions.

Theorem 4 Under the Gross Substitutes condition, if there is a weakly blocking coalition, there must be a basic weakly blocking coalition.

Proof. It suffices to consider blocking coalitions $(j, B)$ with $j \in F$. Suppose we are given a weakly blocking coalition $(j, B)$ for some firm $j \in F$ and worker group $B \subseteq W$. By definition, there exists a salary scheme $t^{j}$ such that $t_{i}^{j}-w_{i}^{j} \geq s_{i}^{\mu(i)}-w_{i}^{\mu(i)}$ for every $i \in B$ and $\pi_{j}\left(B, t^{j}\right) \geq \pi_{j}\left(\mu(j), s^{j}\right)$ with at least one strict inequality.

Now define a new salary scheme $\tilde{t}^{j} \in \mathbf{R}^{W}$ by

$$
\tilde{t}_{i}^{j}=s_{i}^{\mu(i)}-w_{i}^{\mu(i)}+w_{i}^{j}, \quad \forall i \in W .
$$


Observe that $\tilde{t}_{i}^{j}=s_{i}^{\mu(i)}-w_{i}^{\mu(i)}+w_{i}^{j}=s_{i}^{j}$ for every $i \in \mu(j)$, and $\tilde{t}_{i}^{j}=s_{i}^{\mu(i)}-$ $w_{i}^{\mu(i)}+w_{i}^{j} \leq t_{i}^{j}-w_{i}^{j}+w_{i}^{j}=t_{i}^{j}$ for every $i \in B$. Then we have

$$
\pi_{j}\left(B, \tilde{t}^{j}\right) \geq \pi_{j}\left(B, t^{j}\right) \geq \pi_{j}\left(\mu(j), s^{j}\right)=\pi_{j}\left(\mu(j), \tilde{t}^{j}\right) .
$$

It follows from the definition of $(j, B)$ that at least one of the two inequalities in (15) is strict, i.e.,

$$
\pi_{j}\left(B, \tilde{t}^{j}\right)>\pi_{j}\left(\mu(j), \tilde{t}^{j}\right) .
$$

Hence from (16) we have $\mu(j) \notin D^{j}\left(\tilde{t}^{j}\right)$. Now because of the GS condition it follows from the SI property one of the three cases must occur:

(4) there is a worker $k \in W \backslash \mu(j)$ such that

$$
R^{j}(\mu(j) \cup\{k\})-\sum_{i \in \mu(j) \cup\{k\}} \tilde{t}_{i}^{j}>R^{j}(\mu(j))-\sum_{i \in \mu(j)} \tilde{t}_{i}^{j} .
$$

(5) there are a worker $k \in W \backslash \mu(j)$ and a worker $l \in \mu(j)$ such that

$$
R^{j}((\mu(j) \cup\{k\}) \backslash\{l\})-\sum_{i \in(\mu(j) \cup\{k\}) \backslash\{l\}} \tilde{t}_{i}^{j}>R^{j}(\mu(j))-\sum_{i \in \mu(j)} \tilde{t}_{i}^{j} .
$$

(6) there is a worker $k \in \mu(j)$ such that

$$
R^{j}(\mu(j) \backslash\{k\})-\sum_{i \in \mu(j) \backslash\{k\}} \tilde{t}_{i}^{j}>R^{j}(\mu(j))-\sum_{i \in \mu(j)} \tilde{t}_{i}^{j} .
$$

Note that $\tilde{t}_{i}^{j}-w_{i}^{j}=s_{i}^{\mu(i)}-w_{i}^{\mu(i)}=u_{i}$ for all $i \in W$ due to (14). We first consider case (4). Since $u_{i}=\tilde{t}_{i}^{j}-w_{i}^{j}=s_{i}^{j}-w_{i}^{j}$ and $\tilde{t}_{i}^{j}=s_{i}^{j}$ for every $i \in \mu(j)$, and $u_{j}=R^{j}(\mu(j))-\sum_{h \in \mu(j)} \tilde{t}_{i}^{j}=R^{j}(\mu(j))-\sum_{h \in \mu(j)} s_{i}^{j}$, we have

$$
R^{j}(\mu(j) \cup\{k\})-\sum_{i \in \mu(j)} \tilde{t}_{i}^{j}-\tilde{t}_{k}^{j}>u_{j}
$$

which can be written as

$$
u_{j}+\sum_{i \in \mu(i)}\left(u_{i}+w_{i}^{j}\right)+u(k)+w_{k}^{j}<R^{j}(\mu(j) \cup\{k\})
$$

This corresponds to case (1). 
Similarly, using $u_{j}=R^{j}(\mu(j))-\sum_{h \in \mu(j)} \tilde{t}_{i}^{j}=R^{j}(\mu(j))-\sum_{h \in \mu(j)} s_{i}^{j}$, one can show that case (5)

$$
R^{j}((\mu(j) \cup\{k\}) \backslash\{l\})-\sum_{i \in(\mu(j) \cup\{k\}) \backslash\{l\}} \tilde{t}_{i}^{j}>R^{j}(\mu(j))-\sum_{i \in \mu(j)} \tilde{t}_{i}^{j},
$$

implies case (2)

$$
u_{j}+\sum_{i \in \mu(j) \backslash\{l\}}\left(u_{i}+w_{i}^{j}\right)+u(k)+w_{k}^{j}<R^{j}((\mu(j) \cup\{k\}) \backslash\{l\}),
$$

and that case (6) implies case (3).

Under the Gross Substitutes condition we can establish the following major refinement of Theorem 2.

Theorem 5 For the labour market $\left(F, W, R^{j}, w_{i}^{j}\right)$ under the Gross Substitutes condition, there exists a finite number of basic weak coalition improvements with the status quo maintaining rule from an arbitrary market state to a competitive equilibrium.

From this result one can easily write down the corresponding refinement of Theorem 1 under the Gross Substitutes condition. The proof of the above theorem follows from the Procedure in the previous section, Theorem 3 and the next lemma.

Lemma 9 In Step 2 of the Procedure, there exists a finite sequence of basic weak coalition improvements with the status quo maintaining rule from the current $\mu(j)$ to a maximizer $U^{*}$ within $\mu(j) \cup \mu^{*}(j)$.

Proof. Let $p_{k}=u_{k}+w_{k}^{j}$ for every $k \in \mu(j) \cup \mu^{*}(j)$. Consider the following problem

$\max R^{j}(X)-u(X)-w^{j}(X)=R^{j}(X)-\sum_{k \in X} p_{k}$

s.t. $\quad X \subseteq \mu(j) \cup \mu^{*}(j)$

Let $D^{j}(p)$ be the collection of optimal solutions to the problem. Since $D^{j}(p)$ satisfies the Gross Substitutes condition, it satisfies the Single Improvement property. Consequently, there exists a finite sequence of basic weak coalition improvements with the status quo maintaining rule from the current $\mu(j)$ to a maximizer $U^{*}$ within $\mu(j) \cup \mu^{*}(j)$.

It is also possible to obtain a refined version of Theorems 1 and 2 under the Gross Substitutes and Complements condition of Sun \& Yang (2006, 2009). 


\section{CONCLUSION}

Economic processes are fundamental instruments by which markets are operated and equilibrium prices or salaries are generated. Such processes can be roughly classified into two major groups. One group comes out from deliberate human design, such as auctions, which have been widely used to sell mobilephone licenses, electricity, treasure bills, mineral rights, keywords, pollution permits, and many other commodities and services involving a staggering value of hundreds of billions of dollars (see Krishna (2002), Klemperer (2004), and Milgrom (2004)). In some sense, a conscious human design market process like auction, matching and school choice design can be regarded as a visible hand. The other are spontaneous market processes which arise naturally from human economic action but are not designed by human beings. They are perhaps literally the "true" invisible hand as conceived by Adam Smith. Uncoordinated decentralized markets, notably labor markets, are of this nature. While many important results have been obtained for the first type of market processes, we have far less understanding of the second. This paper shed light on the second type of processes - spontaneous market processes-for a large class of decentralized and uncoordinated markets.

In the paper we have analyzed a general decentralized and uncoordinated labour market where heterogeneous self-interested firms and workers meet directly and randomly in pursuit of higher payoffs over time. Each firm hires as many workers as it wishes. Each worker has preferences over firms and salaries but takes at most one position. Each economic agent makes her own decision independently and freely. The information of the market is dispersed among all separate market participants. In other words, information is incomplete to every individual. At any time any firm and any group of workers can form a new coalition if all members in the coalition divide their joint payoff in such a way that makes no member of the coalition worse off and at least one member strictly better off. In the process, the firm may fire some of its own workers and hire workers from other firms and each deserted firm will at least shortly maintain the status quo for its remaining workers. An important feature is that in the process the total welfare need not be monotonic, because every abandoned firm and dismissed worker could be worse off. As information is incomplete and decision-making is decentralized, it is natural to assume that this coalition improvement with the status quo maintaining rule occurs only with a positive probability conditional on the 
current state and time. This spontaneous random decentralized competitive dynamic process exhibits several salient features that are widely observed in real life decentralized markets. We have shown that starting with any initial market state, the spontaneous market process converges almost surely in finite time to a competitive equilibrium, thus resulting in an efficient allocation of resources. The result holds true for any competitive market as long as there exists an equilibrium with an integral vector of equilibrium salaries or prices. An important example for equilibrium existence is the well-known Gross Substitutes condition of Kelso \& Crawford (1982).

Our study provides a theoretical foundation for affirming Adam Smith's Invisible Hand in complex economic environments involving uncertainty, indivisibility and incomplete information and sheds new light on a large class of spontaneous decentralized, random and dynamic market processes. This study also has interesting and meaningful policy implications: Free markets can in general achieve an efficient distribution of resources even in a chaotic, random and imperfect information environment. More specifically, the price system can play a vital role in efficiently communicating information "in a system in which the knowledge of the relevant facts is dispersed among many people, prices can act to coordinate the separate actions of different people in the same way as subjective values help the individual to coordinate the parts of his plan" as Hayek (1945, pp. 525-527) had believed. A word of caution is that in order for free markets to perform well, the government should improve market transparency and offer some coordination among market participants.

Our model is very general and natural in almost all respects but its zero search cost assumption. An important direction for future research is to relax this assumption. For instance, firms and workers do not and cannot always make contact with one another immediately. Firms are trying to find workers and workers are looking for jobs. This search process usually requires resources and time, thus creating frictions in the market; see e.g., Diamond (1971, 1981). How will such search frictions affect efficiency of the market and convergence of the spontaneous process? Another important question is to address the computational complexity issue of the random decentralized dynamic process studied in the current paper.

We hope that the current study will prove to be useful in understanding fundamental issues concerning spontaneous random decentralized market processes in the complex world. 


\section{Appendix}

A state $(\mu, u)$ is weakly blocked by a general coalition $B \subseteq F \cup W$ (i) if there exists one firm $j \in B$ with a payoff vector $r \in \mathbf{R}^{B}$ such that

$$
\begin{gathered}
r_{k} \geq u_{k} \text { for every } k \in B, \text { and } \\
\sum_{k \in B} r_{k}=R^{j}(B \backslash\{j\})-\sum_{k \in B \backslash\{j\}} w_{k}^{j}
\end{gathered}
$$

with at least one strict inequality for (17), or (ii) if the coalition $B$ contains only one worker $i$ with $r_{i}=0>u_{i}$. B is called a general weakly blocking coalition. Notice that this definition does not require every member of the coalition $B$ to be individually rational, i.e., $r_{k} \geq 0$ for all $k \in B$.

A state is a strict core allocation or a competitive equilibrium if it is not weakly blocked by any general coalition. See Kelso \& Crawford (1982, pp. 1487-1488) for this conventional definition. Below we show that using individually rational weakly blocking coalitions can achieve the same competitive equilibrium.

Lemma 10 If a state $(\mu, u)$ is weakly blocked by a general coalition $B$, it must be blocked by an individually rational coalition.

Proof. Because $B$ weakly blocks $(\mu, u)$, there exists $r \in \mathbb{R}^{B}$ such that $r_{k} \geq u_{k}$ for every $k \in B$ with at least one strict inequality. If $r_{k} \geq 0$ for all $k \in B$, we are done. If there is some $r_{k}<0$, then the state $(\mu, u)$ is weakly blocked by the individually rational coalition $\{k\}$ with the payoff $\bar{r}_{k}=0$.

Lemma 11 A state is a competitive equilibrium if it is not weakly blocked by any individually rational coalition.

Proof. Let $(\mu, u)$ be a market state that is not weakly blocked by any individually rational coalition. Suppose that $(\mu, u)$ is weakly blocked by a general coalition $B$. There exists some $k \in B$ such that $u_{k} \leq r_{k}<0$. Then the state $(\mu, u)$ must be weakly blocked by the individually rational coalition $\{k\}$, yielding a contradiction. We have shown that $(\mu, u)$ is not weakly blocked by any general coalition and thus must be a competitive equilibrium.

The above results demonstrate that it is sufficient to focus on individually rational weakly blocking coalitions. 


\section{References}

Arrow, K. J., Block, H. D., \& Hurwicz, L. (1959). On the stability of the competitive equilibrium, II. Econometrica, 27, 82-109.

Arrow, K. J., \& Hahn, F. (1971). General Competitive Analysis. San Francisco: Holden-Day.

Arrow, K. J., \& Hurwicz, L. (1958). On the stability of the competitive equilibrium, I. Econometrica, 522-552.

Ausubel, L. M. (2004). An efficient ascending-bid auction for multiple objects. American Economic Review, 94, 1452-1475.

Ausubel, L. M. (2006). An efficient dynamic auction for heterogeneous commodities. American Economic Review, 96, 602-629.

Ausubel, L. M., \& Milgrom, P. (2002). Ascending auctions with package bidding. Advances in Theoretical Economics, 1 .

Baldwin, E., \& Klemperer, P. (2013). Tropical geometry to analyse demand. Unpublished manuscript, Oxford.

Biró, P., Bomhoff, M., Golovach, P. A., Kern, W., \& Paulusma, D. (2014). Solutions for the stable roommates problem with payments. Theoretical computer science, $\underline{540}, 53-61$.

Chen, B., Fujishige, S., \& Yang, Z. (2016). Random decentralized market processes for stable job matchings with competitive salaries. Journal of Economic Theory, $165,25-36$.

Chung, K.-S. (2000). On the existence of stable roommate matchings. Games and Economic Behavior, 33, 206-230.

Crawford, V. P., \& Knoer, E. M. (1981). Job matching with heterogeneous firms and workers. Econometrica, 437-450.

Demange, G., Gale, D., \& Sotomayor, M. (1986). Multi-item auctions. Journal of Political Economy, 94, 863-872.

Diamantoudi, E., Miyagawa, E., \& Xue, L. (2004). Random paths to stability in the roommate problem. Games and Economic Behavior, 48, 18-28.

Diamond, P. A. (1971). A model of price adjustment. Journal of economic theory, $\underline{3}$, 156-168.

Diamond, P. A. (1981). Mobility costs, frictional unemployment, and efficiency. Journal of political Economy, 89, 798-812.

Feldman, A. M. (1974). Recontracting stability. Econometrica, 42, 35-44.

Fisher, F. M. (1972). On price adjustment without an auctioneer. Review of Economic Studies, $39,1-15$.

Fisher, F. M. (1974). The hahn process with firms but no production. Econometrica, $\underline{42}, 471-486$. 
Fisher, F. M. (1989). Disequilibrium Foundations of Equilibrium Economics. New York: Cambridge University Press.

Fujishige, S., \& Yang, Z. (2015). Decentralised random competitive dynamic market processes. Economics Working Paper No.1527, University of York.

Gale, D., \& Shapley, L. (1962). College admissions and the stability of marriage. American Mathematical Monthly, 69, 9-15.

Green, J. (1974). The stability of Edgeworth's recontracting process. Econometrica, $42,21-34$.

Gul, F., \& Stacchetti, E. (1999). Walrasian equilibrium with gross substitutes. Journal of Economic theory, 87, 95-124.

Gul, F., \& Stacchetti, E. (2000). The English auction with differentiated commodities. Journal of Economic theory, 92, 66-95.

Hahn, F. (1958). Gross substitutes and the dynamic stability of general equilibrium. Econometrica, 26, 169-170.

Hahn, F. (1962). On the stability of a pure exchange equilibrium. International Economic Review, 3, 206-213.

Hahn, F., \& Negishi, T. (1962). A theorem on non-tâonnement stability. Econometrica, 30, 463-469.

Hatfield, J. W., \& Milgrom, P. (2005). Matching with contracts. American Economic Review, 95, 913-935.

Hayek, F. A. (1944). The Road to Serfdom. London: Routledge.

Hayek, F. A. (1945). The use of knowledge in society. American economic review, XXXV, 519-530.

Hayek, F. A. (1988). The Fatal Conceit: The Errors of Socialism. London: Routledge.

Kelso, A., \& Crawford, V. P. (1982). Job matching, coalition formation, and gross substitutes. Econometrica, 50, 1483-1504.

Klaus, B., \& Klijn, F. (2007). Paths to stability for matching markets with couples. Games and Economic Behavior, 58, 154-171.

Klemperer, P. (2004). Auctions: Theory and Practice. Princeton, NJ: Princeton University Press.

Kojima, F., \& Pathak, P. A. (2009). Incentives and stability in large two-sided matching markets. American Economic Review, 99, 608-627.

Kojima, F., \& Ünver, M. U. (2008). Random paths to pairwise stability in many-tomany matching problems: A study on market equilibration. International Journal of Game Theory, 36, 473-488.

Koopmans, T., \& Beckmann, M. (1957). Assignment problems and the location of economic activities. Econometrica, 25, 53-76.

Krishna, V. (2002). Auction Theory. New York: Academic Press. 
Ma, J. (1996). On randomized matching mechanisms. Economic Theory, 8, 377-381.

Ma, J. (1998). Competitive equilibrium with indivisibilities. Journal of Economic Theory, 82, 458-468.

Ma, J., \& Li, Q. (2016). Convergence of price processes under two dynamic double auctions. Journal of Mechanism and Institution Design, 1, 1-44.

Milgrom, P. (2000). Putting auction theory to work: The simultaneous ascending auction. Journal of political economy, 108, 245-272.

Milgrom, P. (2004). Putting Auction Theory to Work. Cambridge: Cambridge University Press.

Milgrom, P., \& Strulovici, B. (2009). Substitute goods, auctions, and equilibrium. Journal of Economic theory, 144, 212-247.

Murota, K. (2016). Discrete convex analysis: A tool for economics and game theory. Journal of Mechanism and Institution Design, 1, 151-273.

Nax, H., \& Pradelski, B. (2015). Evolutionary dynamics and equitable core selection in assignment games. International Journal of Game Theory, 44, 903-932.

Negishi, T. (1961). On the formation of prices. International Economic Review, 2 , 122-126.

Negishi, T. (1962). The stability of a competitive economy: A survey article. Econometrica, 30, 635-669.

Ostrovsky, M. (2008). Stability in supply chain networks. American Economic Review, 98, 897-923.

Perry, M., \& Reny, P. (2005). An efficient multi-unit ascending auction. Review of Economic Studies, 72, 567-592.

Quinzii, M. (1984). Core and competitive equilibria with indivisibilities. International Journal of Game Theory, 13, 41-60.

Roth, A., \& Sotomayor, M. (1990). Two-Sided Matching. New York: Cambridge University Press.

Roth, A., \& Vande Vate, J. (1990). Random paths to stability in two-sided matching. Econometrica, 58, 1475-1480.

Samuelson, P. (1941). The stability of equilibrium: Comparative statics and dynamics. Econometrica, 9, 97-120.

Samuelson, P. (1948). Foundations of Economic Analysis. Cambridge, MA: Harvard University Press.

Scarf, H. (1960). Some examples of global instability of the competitive equilibrium. International Economic Review, 1, 157-172.

Scarf, H. (1973). The Computation of Economic Equilibria. New Haven, CT: Yale University Press.

Shapley, L., \& Scarf, H. (1974). On cores and indivisibility. Journal of mathematical economics, $1,23-37$. 
Shapley, L., \& Shubik, M. (1971). The assignment game I: The core. International Journal of game theory, 1, 111-130.

Smith, A. (1776). The Wealth of Nations. London: W. Strahan and T. Cadell.

Sun, N., \& Yang, Z. (2006). Equilibria and indivisibilities: Gross substitutes and complements. Econometrica, 74, 1385-1402.

Sun, N., \& Yang, Z. (2009). A double-track adjustment process for discrete markets with substitutes and complements. Econometrica, 77, 933-952.

Sun, N., \& Yang, Z. (2014). An efficient and incentive compatible dynamic auction for multiple complements. Journal of Political Economy, 122, 422-466.

Uzawa, H. (1962). On the stability of edgeworth's barter process. International Economic Review, 3, 218-232.

Walras, L. (1874). Elements of Pure Economics. Lausanne: L. Corbaz.

Wilson, R. (1987). Game-theoretic analyses of trading processes. In T. Bewley (Ed.), Advances in Economic Theory: Fifth World Congress (p. 33-70). Cambridge: Cambridge University Press. 